\title{
Reflexões Éticas Suscitadas pelos Avanços Tecnológicos
}

\author{
Andrey Tavares da Silva ; Allan Richards de Melo Nunes Morais ${ }^{2}$; \\ Fernanda Coelho de Figueiredo Soares Nascimento ${ }^{3}$; Júlio Cezar Costa Ramos ${ }^{4}$; \\ Tiago Gama do Nascimento ${ }^{5}$; Francisco Ricardo Duarte 6
}

\begin{abstract}
Resumo: Este artigo faz uma análise das transformações que o uso das novas tecnologias, que surgiram na sociedade pós-moderna e contemporânea, sobre a conduta moral dos indivíduos e suas implicações éticas. Dessa forma buscou-se identificar na literatura a fundamentação teórica dos conceitos. O método de pesquisa constituiu no levantamento bibliográfico dos conceitos, juntamente com análise de artigos e acontecimentos relevantes sobre a utilização das tecnologias. É destacado quatro tecnologias que se desenvolveram no último século - data mining, manipulação genética, energia nuclear, redes sociais - para analisar as transformações e reflexões éticas que essas tecnologias trouxeram para o comportamento moral dos indivíduos. Essas reflexões são elencadas e discutidas a luz dos conceitos levantados na pesquisa bibliográfica. Por fim nas considerações finais é ponderado as reflexões éticas colocadas no texto.
\end{abstract}

Palavras-chave: Ética; Moral; Tecnologia; Sociedade Contemporânea.

\section{Ethical Reflections Sustained by Technological Advances}

\begin{abstract}
This article makes an analysis of the transformations that the use of the new technologies, that have appeared in the postmodern and contemporary society, on the moral conduct of the individuals and their ethical implications. In this way, we tried to identify in the literature the theoretical basis of the concepts. The research method consisted in the bibliographic survey of the concepts, along with an analysis of relevant articles and events on the use of technologies. Four technologies that have developed in the last century - data mining, genetic manipulation, nuclear energy, social networks - have been highlighted to analyze the transformations and ethical reflections that these technologies have brought to the moral behavior of individuals. These reflections are listed and discussed in light of the concepts raised in the bibliographic research. Finally, in the final considerations, the ethical reflections placed in the text are considered.
\end{abstract}

Keywords: Ethics; Moral; Technology; Contemporary Society.

\footnotetext{
${ }^{1}$ Graduação em Análise e Desenvolvimento de Sistemas pela Universidade Norte do Paraná, Brasil.

${ }^{2}$ Especialização em Ensino Superior, Contemporaneidade e Novas Tecnologias pela Universidade Federal do Vale do São Francisco. Mestrado em Administração Pública pela UNIVASF;

${ }^{3}$ Universidade Federal Vale do São Francisco - UNIVASF;

${ }^{4}$ Universidade Federal Vale do São Francisco - UNIVASF. Autor Correspondente. Contato: juliooccr@gmail.com;

${ }^{5}$ Graduação em Engenharia Civil pela Universidade Federal do Vale do São Francisco, Especialização em Estruturas de Concreto e Fundações pela Universidade Cidade de São Paulo.

Rede Metropolitana do Vale do São Francisco, Brasil;

${ }^{6}$ Universidade Federal Vale do São Francisco - UNIVASF.
} 


\section{Introdução}

Este artigo tem como objetivo refletir sob o impacto das tecnologias na conduta ética dos indivíduos, a partir de conceitos do que venha a ser a ética e a moral na sociedade pósmoderna e contemporânea. Os avanços tecnológicos do último século - computadores, energia nuclear, engenharia genética, internet - aceleraram as transformações sociais, culturais e econômicas em nossa sociedade. Esse cenário, de mudanças constantes e rápidas, é inédito para o pensamento moral e ético.

A moral e a ética fazem parte da vida em sociedade. Para Romiero (2009) o conjunto de valores estabelecidos ao longo dos tempos formam a moral. Ou seja, a moral está diretamente relacionada com a temporalidade, uma vez que as normas - que definem o que é certo ou errado - mudam no decorrer da história, a moral também se altera.

Romiero afirma que:

Ética é a parte da filosofia que busca refletir sobre o comportamento humano do ponto de vista das noções de bem e de mal, de justo e de injusto. Tem duplo objetivo: a) elaborar princípios de vida capazes de orientar o homem para uma ação moralmente correta; b) refletir sobre os sistemas morais elaborados pelos homens. Portanto, ética é a consciência filosófica aplicada à moral (ROMIERO, 2009, p. 29).

Percebemos que os conceitos de moral e ética convergem para um ponto, sendo esta um produto da moral. A moral é o conjunto de regras estabelecidas para o convívio em sociedade. A ética é uma análise crítica dessas regras sob a perspectiva da filosofia. Como resultado, as reflexões éticas, podem contestar e propor mudanças nas regras estabelecidas pela moral.

A sociedade pós-moderna exige das organizações um alto grau de tecnologia e inovação. Todos os dias novos produtos e serviços chegam ao mercado e outros ficam obsoletos. Essa busca acelerada por inovação proporcionou o surgimento de novas tecnologias - data mining, manipulação genética, energia nuclear, redes sociais - que alteram a maneira de indivíduos e organizações agirem na sociedade.

Portanto, dada a relevância do que é moral e ético em se tratando do uso das tecnologias, iremos analisar as novas questões éticas e morais provocadas pelas inovações tecnológicas da sociedade contemporânea. Assim, este artigo está estruturado da seguinte forma: introdução, método, desenvolvimento da temática - ética e tecnologia na sociedade contemporânea, reflexão sobre as novas questões éticas e considerações finais. 


\section{Método}

Buscou-se identificar na literatura a fundamentação teórica dos temas abordados. O método de pesquisa constituiu no levantamento bibliográfico dos conceitos, juntamente com análise de artigos e acontecimentos relevantes sobre a utilização das tecnologias.

Os conceitos e assuntos relativos ao tema utilizados para elaboração desse trabalho, de forma resumida, estão relacionados no quadro 01:

\begin{tabular}{|l|l|}
\hline Conceitos & Autores \\
\hline Ética & $\begin{array}{l}\text { ROMIERO (2009); DUPAS (2001); } \\
\text { BAUMAN (2017) }\end{array}$ \\
\hline Medicina & FRIAS (2013) \\
\hline Tecnologia & PINTO (2005) \\
\hline Data mining & $\begin{array}{l}\text { XU (2014); JIANG (2014); WANG (2014) } \\
\text { YUAN (2014); REN (2014) }\end{array}$ \\
\hline Energia Nuclear & XIANG (2011); ZHU (2011) \\
\hline
\end{tabular}

Quadro 1: Temas éticos e seus respectivos autores abordados nesse artigo.

Fonte: Elaboração do autor (2018)

Através das ideias e conceitos desenvolvido por esses autores em seus trabalhos, este artigo traz reflexões sobre o impacto que algumas das tecnologias desenvolvidas no último século tiveram no comportamento moral e pensamento ético da sociedade contemporânea.

\section{Tecnologia e Ética na Sociedade Contemporânea}

Para Pinto (2005) o conceito de tecnologia pode ser compreendido sob quatro perspectivas: no sentido etimológico, no sentido de conhecimento técnico, no sentido de desenvolvimento produtivo e no sentido ideológico. Na percepção etimológica, o termo tecnologia é de origem grega, formado por tekne ("arte, técnica ou ofício") e por logos (“conjunto de saberes"). É utilizado para definir os conhecimentos que permitem construir e modificar o meio ambiente, com o objetivo de satisfazer as necessidades humanas.

Se observarmos a tecnologia apenas como uma ferramenta para construir alguma coisa, seremos incapazes de percebermos as implicações morais e éticas que a mesma possui. Para perceber as implicações éticas, é necessário observar as transformações no comportamento dos indivíduos, uma vez que, esse comportamento poderá refletir na conduta moral do indivíduo na sociedade. 
Para Dupas (2001) o desenvolvimento tecnológico contemporâneo teve um "turning point" a partir do momento em que o sistema capitalista passou a ser o único fomentador da inovação. Dupas escreveu: “o capitalismo global apossou-se por completo dos destinos da tecnologia, libertando-a de amarras metafísicas e orientando-a única e exclusivamente para a criação de valor econômico (DUPAS, 2001, p. 14).

Como consequência da ênfase na criação de valor econômico, é perceptível uma maior valorização da técnica em detrimento dos valores éticos e das normais morais. O "sabe-fazer" afastou-se do "saber-porque-fazer". Enquanto um é focado em resultados pragmáticos, o outro possibilita ter uma maior amplitude dos resultados de suas ações, englobando suas implicações éticas. Ainda segundo Dupas, esse novo comportamento alterou de maneira negativa a forma de agir dos indivíduos:

A dominação do econômico sobre o social operou sucessivas degradações, primeiro
do "ser" para o "ter", em seguida do "ter" para o "parecer-ter". Às atuais massas
excluídas resta apenas o "identificar-se-com-quem-parece-ser-ou-ter" através do
espetáculo a distância, um virtual feito real pelas mídias globais (DUPAS, 2001, p.
102).

Esse comportamento foi potencializado com o surgimento das redes sociais. A popularização da internet a partir dos anos 2000 permitiu as redes sociais ocuparem um grande espaço na vida social e cultural dos indivíduos. Surgiram diversas redes: o Myspace (2003), o Linkedin (2003), o o Orkut (2004), o Facebook (2004), o Twitter (2006), o Instagram (2010), o Google+ (2011). O Facebook é a maior rede com 1 bilhão de usuários ativos e tem como proposta conectar familiares, amigos, conhecidos e organizações em uma rede de interesses comuns e compartilhados.

As pessoas (jovens, em sua essência) estão formando suas opiniões espelhadas nas idéias dos chamados digital influencer, buscando o "identificar-se-com-quem-parece-ser-outer”. Os influenciadores digitais são pessoas bem relacionadas no nas redes sociais, com alcance de voz e imagem a milhões de pessoas.

Além das redes sociais, o desenvolvimento das TICs - Tecnologias de Informação e Comunicação - nas últimas décadas permitiu o desenvolvimento de uma nova tecnologia para gestão de grande quantidade de dados - o data mining. Essa tecnologia permitir analisar e descobrir padrões em grandes conjuntos de dados. Possibilitando criar mecanismos automatizados para identificar tendências de comportamento a partir do relacionamento de informações de diversas fontes de dados. Para Xu, Jiang, et. al., (2014) a crescente 
popularidade e o desenvolvimento das tecnologias de data mining trazem uma séria ameaça à segurança das informações confidenciais dos indivíduos.

Sob a perspectiva da privacidade, o uso das TICs precisa ser analisado com cautela. Ao mesmo tempo, em que o acesso confidencial e irrestrito a rede permite a livre e rápida propagação de novas idéias, como por exemplo a Primavera Árabe (série de revoltas populares contra diversos governos nacionais do mundo árabe), o surgimento de sites como o Wikileaks (organização sem fins lucrativos que publica em seu site documentos confidenciais vazados de governos e empresas), ela também pode ser usada para vigiar a própria sociedade civil, como por exemplo as denúncias feitas por Snowden (de que programas de computadores foram desenvolvidos pelo governo americano para espionar seus indivíduos e organizações), assim como para práticas de crimes virtuais.

Outra área com avanço significativo foi a biogenética. As novas perspectivas da biomédica com o avanço das pesquisas sobre a manipulação genética do DNA humano podem alterar alguns valores morais da sociedade. Dessa forma, surgiu novas questões éticas para reflexão, como a possibilidade de análise do genoma humano para realizar modificações genéticas em indivíduos.

Segundo Frias (2013), os avanços na área biomedicina ao longo do tempo sempre trouxeram ao debate novas questões éticas:

Desde os anatomistas do século XIV e dos fisiologistas do século XVII, de The Descent of Men até a genômica funcional e as pesquisas com células-tronco embrionárias humanas, a biologia empreendeu/motivou questionamentos sobre os fundamentos de nossa visão do homem (FRIAS, 2013, p. 2).

Por se tratar de conhecimento teórico difícil de ser explicado para quem não é da área, a evolução das pesquisas genéticas não é de conhecimento comum. Até que uma notícia na mídia chame a atenção e novas questões morais e éticas são levantadas.

Para Frias,

Tais questionamentos, porém, se tornam presentes à sociedade em geral especialmente quando resultam em tecnologia médica, especialmente através da invenção de fármacos (inclusive vacinas, antibióticos, anestesias, psicotrópicos, anticoncepcionais etc.), que alteram significativamente a fisiologia humana, e de intervenções cirúrgicas agressivas (transplantes, hemodiálise, transfusão de sangue, próteses etc.), que artificializam o corpo humano. No entanto, esses questionamentos tornaram-se urgentes quando os avanços em tecnologia médica chegaram à reprodução humana através de técnicas de reprodução assistida (fertilização in vitro, inseminação artificial, barrigas-de-aluguel, descarte seletivo de embriões etc.) (FRIAS, 2013, p. 2). 
Outra tecnologia que surgiu no último século foi a da energia nuclear. A energia nuclear é considerada uma fonte de energia eficiente do ponto de vista econômico, que reduz as emissões de gás carbono. Por outro lado, o combustível nuclear e os resíduos são altamente nocivos ao meio ambiente. E os efeitos de um acidente são catastróficos, vide Chernobyl e Fukushima. Para Xiang (2011, p. 4) as questões éticas sobre a energia nuclear estão na comparação entre os benefícios e riscos, o impacto catastrófico de acidentes nucleares e na legislação específica para o tema.

\section{Novas questões}

Iremos perceber que novas questões surgem quando o surgimento de uma nova tecnologia altera (aumenta ou diminui) o poder dos indivíduos e organizações. A busca pela inovação, em alguns casos, pode levar ao surgimento de tecnologias onde o seu proposito por si é um novo dilema.

Por exemplo, a biomedicina e a biogenética através do desenvolvimento de métodos para manipulação de genes do DNA, clonagem biológica de indivíduos com o objetivo de obter organismo transgénicos biologicamente "melhores" para um determinado fim, é eticamente questionável do ponto de vista moral e do ponto de vista biológico.

Para Frias (2013) esse debate possui uma grande quantidade de questões que ele estruturou da seguinte forma:

a) Problema da Pesquisa: testes de técnicas de intervenção genética em adultos devem ser realizados quando não há tratamento possível? E em fetos e embriões? A pesquisa com células-tronco embrionárias deve ser permitida? E a clonagem terapêutica?

b) Problema dos Organismos Geneticamente Modificados: temos o direito de interferir na estrutura dos organismos (vegetais, animais e bactérias)? Organismos geneticamente modificados podem aumentar a dependência dos países subdesenvolvidos?

c) Problema da Propriedade Intelectual: É possível haver um proprietário de genes e outras parcelas de DNA (ou proteínas ou RNA)? Se sim, quem tem o direito? Como deve acontecer a participação das empresas privadas no patenteamento das biotecnologias genéticas, gênicas e genômicas?

d) Problema da Liberdade: genes são responsáveis pelo comportamento das pessoas? Há implicações quanto à responsabilidade moral e legal dos agentes nas descobertas genéticas? 
e) Problema da Reprodução: quanto os pais devem poder decidir na reprodução assistida? Como isso pode afetar o futuro da criança? Como distinguir entre terapia e melhoramento?

f) Problema da Desigualdade: como a informação genética pessoal afetará a percepção social e individual das pessoas? E das comunidades minoritárias? A intervenção genética é uma ferramenta ou um empecilho à justiça distributiva? Sua liberação aumentará a desigualdade social?

g) Problema da Privacidade: quem deve ter acesso à informação genética pessoal? Estado, seguradoras, empregadores, tribunais, escolas, agências de adoção, militares, polícia?

O fato é que o campo da engenharia genética está se desenvolvendo para permitir ao homem entrar em um laboratório e alterar o "algoritmo" de criação da vida. Algoritmo testando e aprimorado desde o surgimento da vida na terra com base em um método de tentativa e erro tendo como objetivo de perpetuação da vida. No nosso modelo, estamos motivados pela busca de valor econômico, o que pode "quebrar" a estabilidade do algoritmo anterior.

Outro exemplo, é a relação da privacidade com a liberdade e com a segurança no uso das TICs. Pertencemos a uma cultura que preza pela transparência e, ao mesmo tempo, a não garantia da proteção da privacidade dos indivíduos. Isso é um dilema.

$\mathrm{O}$ anonimato e a liberdade no uso das redes sociais permitem a propagação de novas ideias em uma velocidade e alcance sem precedentes. Essas características contribuíram para a Primavera Árabe, que em um período curto de aproximadamente um ano, modificou os regimes de três países - Tunísia, Líbia e Egito. Movimentos semelhantes no passado, levaram décadas para atingir o mesmo resultado.

Ao mesmo tempo, essas mesmas características são utilizadas para a prática de crimes virtuais como cyberbullying, estelionato, comercio ilegal e terrorismo. Esses fatos estão sendo utilizados pelos governos como justificativa para implementar legislações e agências estatais para supostamente monitorar as atividades ilegais praticadas.

No entanto, as denúncias feitas pelo caso Snowden, mostraram o que os governos não conseguem impor limites a si mesmo. Certamente se os governos dos estados árabes tivessem acesso as tecnologias da NSA - National Security Agency, a Primavera Árabe não teria atingindo os mesmos resultados.

O desenvolvimento da tecnologia de energia nuclear também trouxe novas questões éticas. Por exemplo, a preferência por fontes de energia com base em queima de carbono e nuclear - poluentes e de alto impacto ao meio ambiente - prevaleceu sobre as opções de energia 
renováveis e não poluentes. Certamente essa preferência nos permitiu acesso a energia mais barata, porém, são extremamente prejudiciais e perigosas ao nosso meio ambiente.

Para Xiang:

\begin{abstract}
No mundo ocidental, o utilitarismo é uma teoria dominante que valoriza o máximo bem-estar para a maioria das pessoas. Se alguém aplica a visão do utilitarismo ao programa de energia nuclear, as questões-chave são: o programa de energia nuclear maximiza o bem-estar da maioria das pessoas e existem opções alternativas para alcançar o mesmo resultado? Os defensores da energia nuclear, incluindo muitos governos em todo o mundo e organizações internacionais, enfatizam que a energia nuclear é sustentável, limpa e, em geral, segura, deve ser desenvolvida para substituir a energia de combustíveis fósseis (Newton-Small, 2005). Eles afirmam que os acidentes são casos isolados e que não devem dissuadir a humanidade de usar energia nuclear (XIANG, 2011, p. 7) .
\end{abstract}

Sob essa perspectiva o desenvolvimento e o uso da energia nuclear é benéfico já que produz uma energia mais limpa em relação a queima de combustíveis fosseis. E os riscos de acidentes é aceitável perante os benefícios proporcionados pelo uso da energia nuclear. Para Xiang (2011) esses riscos também podem ser minimizados com a adoção de políticas e normas adequadas no uso dessa tecnologia.

\title{
Considerações Finais
}

A ação do homem pós-moderno está pautada nos princípios do sistema econômico, libertando-se de amarras metafísicas, das ideias do iluminismo e orientando suas ações na busca de valor financeiro. Este sistema estimula o homem optar pelo "ter" em detrimento do "ser", com isto o comportamento social pode estabelecer julgamentos em que os fins justificam os meios. O estimulo financeiro certamente permitiu um avanço acelerado e resultados pragmáticos para sociedade. Entretanto esta motivação deixa de lado ou dar menos importâncias para outras perspectivas, como a ambiental, a ética e a moral.

Sobre o uso da energia nuclear, Xiang (2011) defende que a ela pode ser utilizada de uma maneira sustentável e ajudar a reduzir e emissão de gazes poluentes. Para isso as autoridades e a indústria precisam adotar uma abordagem mais rigorosa sobre os programas nucleares, melhorando a segurança, a gestão de riscos e exigindo uma divulgação completa e aberta com ao público.

No pêndulo entre liberdade e segurança no uso das TICs, podemos resgatar o as idéias de Bauman (2017) de que a nossa civilização é uma gangorra entre liberdade e segurança (via Estado), ao escolher a liberdade, é preciso abrir mão de segurança; ao escolher segurança, é 
preciso abrir mão de liberdade. Ele caracterizou esse pensamento como uma dicotomia, que em sua opinião, é insolúvel.

Dupas (2001, p. 119) defende o controle social sobre o uso da tecnologia - o setor privado tomou conta das grandes decisões. Deve haver um resgate no papel do estado: "Na sociedade pós-moderna, o Estado, se autêntico representante da sociedade civil, deveria ter a função de garantir essas condições que permitam fazer prevalecer a justiça sobre o valor econômico". Sob esta perspectiva, certamente é necessário aprimorar o modelo estabelecido para encontrar um meio de alinhar objetivos econômicos imediatos com sustentabilidade ambiente a médio e longo e uma reflexão dos princípios morais e éticos com mais capilaridade.

\section{Referências}

BAUMAN, Zygmunt; Dessal, Gustavo (2017-05-04). O retorno do pêndulo: Sobre a psicanálise e o futuro do mundo líquido (Kindle Locations 35-38). Zahar. Kindle Edition.

DUPAS, Gilberto. Ética e Poder na Sociedade da Informação. São Paulo: Editora UNESP, 2001.

FRIAS, Lincoln. Ética e genética: a moral da medicina genética corretiva. Veritas, v. 58, n. 1, 2013, p. 99-117.

LEI XU, Chunxiao Jiang; WANG, Jian; YUAN, Jian; REN, Yong. Information Security in Big Data: Privacy and Data Mining. In: IEEE Access, vol. 2, pp. 1149-1176, 2014.

PINTO, A. V. O Conceito de Tecnologia. Rio de Janeiro: Editora Contraponto,2005. v I e II.

ROMEIRO, Artieres Estevão. Fundamentos Filosóficos: Noções de Ética, Estética, Política e Metafísica. Batatais-SP: Claretiano, 2009.

XIANG, Hui; ZHU, Yi. The Ethics Issues of Nuclear Energy: Hard Lessons Learned from Chernobyl and Fukushima. The Online Journal of Health Ethics. v. 7, n 2. 2011, artigo 6.

\section{Como citar este artigo (Formato ABNT):}

SILVA, Andrey Tavares da; MORAIS, Allan Richards de Melo Nunes; NASCIMENTO, Fernanda Coelho de Figueiredo Soares; RAMOS, Júlio Cezar Costa; NASCIMENTO, Tiago Gama do; DUARTE, Francisco Ricardo. Reflexões Éticas Suscitadas pelos Avanços Tecnológicos. Id on Line Rev.Mult. Psic., 2019, vol.13, n.43, p. 1072-1080. ISSN: 1981-1179.

Recebido: 11/12/2018;

Aceito: $12 / 12 / 2018$ 